\title{
Diagnósticos de enfermagem relacionados à sexualidade de idosos: Contribuições para a prática.
}

Edison Vitório de Souza Júnior ${ }^{1}$, Brenaráise Freitas Martins dos Santos ${ }^{2}$, Débora Fraga de Souza ${ }^{3}$, Vaniele Pereira Sampaio ${ }^{4}$, Franciele Soares Balbinote ${ }^{5}$, Namie Okino Sawada 6

${ }^{1}$ Enfermeiro, Doutorando em Ciências pelo Programa de Pós-Graduação Enfermagem Fundamental, Universidade de São Paulo EERP/USP), Escola de Enfermagem de Ribeirão Preto, Ribeirão Preto, São Paulo, Brasil. ORCID: 0000-0003-0457-0513

${ }^{2}$ Fisioterapeuta, Mestranda pelo Programa de Pós-Graduação em Enfermagem e Saúde da Universidade Estadual do Sudoeste da Bahia (PPGES/UESB), Jequié, Bahia, Brasil. ORCID: 0000-0002-5271-7543

${ }^{3}$ Enfermeira, Graduada em Enfermagem pela Universidade Estadual do Sudoeste da Bahia (UESB), Jequié, Bahia, Brasil. ORCID: 00000002-2239-0965

${ }^{4}$ Enfermeira, Graduada em Enfermagem pela Universidade Estadual do Sudoeste da Bahia (UESB), Jequié, Bahia, Brasil. ORCID: 00000002-6301-1116

${ }^{5}$ Enfermeira, Graduada em Enfermagem pela, Universidade Estadual do Sudoeste da Bahia (UESB), Jequié, Bahia, Brasil. ORCID: 00000002-2502-9892

${ }^{6}$ Enfermeira, Doutora em Enfermagem, Titular-livre do Programa de Pós-Graduação da Universidade Federal de Alfenas (UNIFAL), Alfenas, Minas Gerais, Brasil. ORCID: 0000-0002-1874-3481

\section{Información del artículo}

Recibido: 02-10-2020

Aceptado: 26-02-2021

DOI:

10.15517/revenf.v0i41.44087

\section{Correspondencia}

Edison Vitório de Souza

Júnior

Escola de Enfermagem de

Ribeirão Preto da

Universidade de São Paulo

(EERP/USP), Ribeirão Preto,

São Paulo, Brasil.

Email: edison.vitorio@usp.br

\section{RESUMO}

Objetivo: Considerando o crescente envelhecimento populacional e as evidências científicas de que a sexualidade na população idosa não é abordada com frequência nos serviços de saúde, o presente estudo contribui de forma significativa para as práticas de enfermagem. O objetivo desse estudo foi identificar na literatura situações relacionadas à sexualidade dos idosos e, por meio delas, traçar diagnósticos de enfermagem tendo como suporte teórico a North American Nursing Diagnosis Association (NANDA 2018-2020).

Metodologia: Trata-se de uma revisão integrativa da literatura construída a partir de 15 artigos originais selecionados sistematicamente na BVS, SciELO, Pubmed, Lilacs, BDENF, IBECS, ScienceDirect, Scopus, Web of Science e Google Scholar.

Resultados: Traçou-se 29 diagnósticos distribuídos nos seguintes domínios: Promoção da saúde 3(10,3\%); Atividade/repouso 3(10,3\%); Percepção/cognição 4(13,9\%); Autopercepção 5(17,2\%); Papéis e relacionamentos 2(6,9\%); Sexualidade 1(3,4\%); Enfrentamento/tolerância ao estresse 3(10,3\%); Princípios da vida 2(6,9\%); Segurança/proteção 4(13,9\%) e Conforto 2(6,9\%). O domínio 
"Autopercepção", foi o domínio que apresentou mais evidências nos estudos. Isso nos faz refletir sobre o poder que cada indivíduo detém, adquirido por meio da evolução de toda conjuntura político-social, que em diversas épocas moldam as suas crenças, atitudes e comportamentos.

Conclusão: Chama-se a atenção da enfermagem que deve estar atenta com mais profundidade aos aspectos que permeiam a subjetividade e os valores pessoais dos idosos e, por meio desse estudo, haverá o direcionamento e a facilitação da assistência frente à sexualidade desse grupo etário.

Palavras-chave: Envelhecimento; Envelhecimento-Saudável; Processo-deEnfermagem. Saúde-do-Idoso; Saúde-Pública

\section{RESUMEN}

\section{Diagnósticos de enfermería relacionados con la sexualidad de las personas adultas mayores: contribuciones a la práctica.}

Objetivo: Considerando el creciente envejecimiento de la población y la evidencia científica de que la sexualidad en la población adulta mayor no se aborda con frecuencia en los servicios de salud, el presente estudio contribuye significativamente a las prácticas de enfermería. El objetivo de este estudio fue identificar en la literatura situaciones relacionadas con la sexualidad de las personas adultas mayores $\mathrm{y}$, a través de ellas, elaborar diagnósticos de enfermería, con el apoyo teórico de la Asociación Norteamericana de Diagnóstico de Enfermería (NANDA 2018-2020).

Metodología: Es una revisión integradora de la literatura construida a partir de 15 artículos originales seleccionados sistemáticamente en la BVS, SciELO, Pubmed, Lilacs, BDENF, IBECS, ScienceDirect, Scopus, Web of Science y Google Scholar.

Resultados: Se rastrearon 29 diagnósticos en los siguientes dominios: Promoción de la salud 3 (10.3\%); Actividad/descanso 3 (10.3\%); Percepción/cognición 4 (13.9\%); Autopercepción 5 (17.2\%); Roles y relaciones 2 (6.9\%); Trastorno sexual 1 (3.4\%); Afrontamiento/tolerancias hasta 3 (10.3\%); Principios de la vida 2 (6.9\%); Seguridad/protección 4 (13.9\%) y Conforto 2 (6.9\%). El dominio "Autopercepción" fue el dominio que presentó más evidencia en los estudios.

Conclusión: Esto nos hace reflexionar sobre el poder que tiene cada persona, adquirido a través de la evolución de toda la situación político-social, que en diferentes momentos configuran sus creencias, actitudes y comportamientos. Con este estudio, se llama la atención a la enfermería, que debe dar mayor importancia a los aspectos relacionados con la subjetividad y los valores personales de las personas mayores, asimismo, se dará una orientación y facilitación de los cuidados ante la sexualidad de este grupo etario. 
Palabras claves: Envejecimiento; Envejecimiento-Saludable; Proceso-deEnfermería; Salud-del-Anciano; Salud-Pública.

\section{ABSTRACT \\ Nursing diagnoses related to the sexuality of elderly: Contributions to practice.}

Aim: Considering the growing population ageing and the scientific evidence that sexuality in the elderly population is not frequently addressed by health services, the present study contributes significantly to nursing practices. The aim of this study was to identify in the literature situations related to the sexuality of elderly citizens and draw nursing diagnoses with the theoretical support of the North American Nursing Diagnosis Association (NANDA 20182020).

Methods: It is an integrative review of the literature constructed from 15 systematically selected original articles; these were retrieved from VHL, SciELO, Pubmed, Lilacs, BDENF, IBECS, ScienceDirect, Scopus, Web of Science and Google Scholar.

Results: A total of 29 diagnostics were traced in the following domains: health promotion 3 (10.3\%); activity / rest 3 (10.3\%); perception / cognition 4 (13.9\%); self-perception 5 (17.2\%); roles and relationships 2 (6.9\%); sexual disorder 1 (3.4\%); coping / tolerances up to 3 (10.3\%); principles of life 2 (6.9\%); security / protection $4(13.9 \%)$ and comfort 2 (6.9\%). The domain "self-perception" was the domain that presented more evidence in the studies.

Conclusion: This makes one reflect on the power that each individual has acquired through the evolution of the entire social-political situation which at different times shapes the beliefs, attitudes and behaviors of the population. It has been drawn to the attention of nursing professionals that they must pay more attention to the aspects that permeate the subjectivity and personal values of elderly citizens, and, through this study, there will be the direction and ease of assistance in the face of sexuality of this age group.

Keywords: Aging; Healthy-Aging; Nursing-Process; Health-of-the-Elderly; PublicHealth

\section{INTRODUÇÃO}

A sexualidade é um componente-chave do comportamento e personalidade humana, sendo considerada como uma das necessidades humanas básicas ${ }^{1}$. Todavia, diante dos preconceitos, mitos e tabus referentes à sexualidade entre os idosos, dissemina-se a desvalorização da temática na sociedade e desconsidera-se que os idosos também possuem desejos ${ }^{2}$. Não obstante, no contexto cultural em que a sexualidade é estritamente representada por meio da penetração sexual, os idosos expressam sentimentos de exclusão, visto que 


\section{Revista Electrónica Enfermería Actual en costa Rica}

as limitações fisiológicas impostas pelo processo de envelhecimento associadas à senilidade, podem interferir no grau de excitação e penetração $0^{2,3}$.

Vale destacar que o termo sexualidade não se limita apenas ao ato sexual, como é amplamente acreditado $^{2}$. Trata-se de uma componente intrínseco a cada indivíduo em todas as fases e aspectos da vida, presente desde o nascimento até a morte. A sexualidade pode ser considerada como identidade estruturante do ser humano e se manifesta por meio de pensamentos, desejos, amor, carinho, intimidade, prazer, dentre outras expressões, constituindo-se, portanto, em uma necessidade humana básica ${ }^{3}$.

Diversos estudos evidenciam a permanência dos desejos sexuais na velhice ${ }^{4}$. Entretanto, muitos profissionais de saúde não abordam a sexualidade em suas rotinas de cuidados para a terceira idade ${ }^{5}$. Como consequência, a supressão da sexualidade nessa faixa etária pode acelerar o processo de envelhecimento e repercutir de forma negativa na saúde $^{6}$ pois já é provado que a sexualidade na velhice promove a manutenção da saúde, qualidade de vida e bem-estar emocional entre os idosos ${ }^{7}$, até mesmo para aqueles que convivem com algum tipo de demência ${ }^{8,9}$, ou com o Vírus da Imunodeficiência Humana $(\mathrm{VIH})^{10}$, sendo este último, um público relevante, pois como o ato sexual faz parte da sexualidade e, os idosos estão cada vez mais ativos sexualmente, torna-se necessário orientações para prevenção de infecções transmitidas por via sexual e, portanto, reduzir a vulnerabilidade dessa população ${ }^{10}$.

Diante desse contexto, justifica-se o desenvolvimento desse estudo, pois por meio da síntese dos principais diagnósticos de enfermagem frente à sexualidade de idosos, haverá o direcionamento e facilitação do processo de trabalho em enfermagem visando cumprir a assistência integral a esta população. Espera-se que, desta forma, os enfermeiros sintam-se aptos em conduzir uma abordagem sobre sexualidade entre os idosos e sintam-se estimulados a buscarem mais evidências científicas que promovam saúde, bem-estar e qualidade de vida a essa população.

Nesta perspectiva, o Processo de Enfermagem é um instrumento metodológico, de cunho científico, que abrange o raciocínio e o julgamento diagnóstico, terapêutico e ético, de modo que sustenta as práticas e aperfeiçoa o cuidado de enfermagem. 0 Processo de Enfermagem possui cinco etapas interdependentes: coleta de dados, diagnósticos de enfermagem, planejamento, implementação e avaliação ${ }^{11}$. Os diagnósticos de Enfermagem estão mundialmente consolidados na North American Nursing Diagnosis Association (NANDA 2018-2020), que os define como o "julgamento clínico sobre uma resposta humana a condições de saúde/processos da vida, ou uma vulnerabilidade a tal resposta, de um indivíduo, uma família, um grupo ou uma comunidade"12.

Identificar diagnósticos de enfermagem que estão consolidados em uma linguagem universal auxilia na gestão de recursos e de pessoal, além da prescrição de intervenções, favorece a educação permanente e fortalece a identidade profissional por meio da delimitação de eventos científicos que pertencem ao escopo de atuação da Enfermagem ${ }^{13}$. Além do mais, a utilização de terminologias padronizadas melhora a comunicação entre os enfermeiros e demais membros da equipe, melhora a continuidade do cuidado, facilita a documentação e torna as práticas de enfermagem mais visíveis ${ }^{14}$. Diante disso, estabeleceu-se a seguinte questão de pesquisa: Quais os principais diagnósticos de enfermagem relacionados à sexualidade de idosos? No intuito de respondê-la, traçou-se o seguinte objetivo: identificar na literatura situações relacionadas à sexualidade dos idosos e, por meio delas, traçar diagnósticos de enfermagem tendo como suporte 


\section{Revista Electrónica Enfermería Actual en costa Rica}

\section{www.revenf.ucr.ac.cr}

teórico a North American Nursing Diagnosis Association (NANDA 2018-2020).

\section{MATERIAIS E MÉTODOS}

O presente estudo refere-se a uma revisão integrativa da literatura elaborada de forma sistematizada por meio das seguintes etapas: "identificação do tema e seleção da questão de pesquisa; estabelecimento de critérios para inclusão e exclusão de estudos/amostragem ou busca na literatura; definição das informações a serem extraídas dos estudos selecionados/categorização dos estudos; avaliação dos estudos incluídos; interpretação dos resultados; e apresentação da revisão/síntese do conhecimento"15:9.

Para a sistematização do percurso metodológico, a busca de artigos foi fundamentada na estratégia PICO. Trata-se de um acrômio que significa População/Problema (P), Intervenção (I), Comparação (C) e Resultados (O), utilizado na construção de revisões e objetiva a qualificação das buscas por meio da delimitação de palavras-chave diretamente relacionadas ao objeto de estudo, que por sua vez, evita buscas desnecessárias e maximiza a identificação de evidências relevantes para atender o objetivo proposto ${ }^{16}$.

Desse modo, o elemento " $\mathrm{P}$ " consistiu em idosos com idade igual ou superior a 60 anos, de ambos os sexos, independentemente de condição clínica; o elemento "I" consistiu na sexualidade de idosos e o elemento " $O$ " consistiu nos fatores que se relacionam com a sexualidade como o carinho, toque, afeto, amor, cuidado, companheirismo, amizade, erotismo, ato sexual, intimidade, masturbação, prazer, dentre outras expressões quanti-qualitativas ${ }^{3,8,17}$, para a partir deles, traçar os diagnósticos de Enfermagem. Vale ressaltar que o elemento " $C$ " não foi utilizado nesse estudo por se configurar uma técnica que não foi utilizada nesta revisão.
A coleta de dados ocorreu em março de 2020 pelos dois primeiros autores de forma independente, responsáveis por todo o processo de busca e seleção dos materiais. Após esta etapa, um terceiro autor interviu como mediador entre os resultados apresentados pelos dois primeiros autores e verificou se os estudos selecionados atenderam aos critérios de inclusão previamente estabelecidos.

As buscas foram realizadas em duas bibliotecas eletrônicas: Biblioteca Virtual em Saúde (BVS) e Scientific Electronic Library Online (Scielo); em sete bases de dados: Literatura Latino-Americana e do Caribe em Ciências da Saúde (Lilacs), Base de Dados de Enfermagem (BDENF), Índice Bibliográfico Espanhol de Ciências de Saúde (IBECS), ScienceDirect, Scopus e Web of Science; em um portal: Pubmed, e em um buscador acadêmico: Google Scholar. Para todas as bases de dados foram utilizados cinco Descritores em Ciências da Saúde (DeCS): "Diagnóstico de enfermagem", "Sexualidade", "Idoso", "Envelhecimento" e "Processo de enfermagem" e cinco Medical Subject Headings (MeSH): "Nursing diagnosis", "Sexuality", "Aged", "Aging" e "Nursing process". Para aumentar a probabilidade de encontrar maior quantitativo de estudos, foram realizadas cinco combinações com os DeCS (D1, D2, D3 D4 e D5) e cinco combinações com os MeSH (M1, M2, M3, M4 e M5), ambos intercalados com 0 operador booleano AND, conforme quadro 1.

Detalhou-se o quantitativo de estudos encontrados nas bases de dados, de acordo com as combinações, conforme tabela 1 . Após esta etapa, os artigos foram submetidos à triagem para identificação, seleção, elegibilidade e inclusão dos que contemplarem à temática, conforme ilustrado na figura 1 . Os critérios de inclusão foram artigos científicos originais, indexados, publicados nos últimos 20 anos (19992019), sem restrição de idiomas e disponíveis de 


\section{Revista Electrónica Enfermería Actual en costa Rica}

forma gratuita para download. Foram excluídos todos os estudos não originais.

\section{Quadro 1}

Combinações de DeCS e MeSH

\section{DECS}

D1 Diagnóstico de enfermagem; Sexualidade; Idoso; Envelhecimento; Processo de enfermagem

D2 Diagnóstico de enfermagem; Sexualidade; Idoso

D3 Diagnóstico de enfermagem; Sexualidade; Envelhecimento

D4 Processo de enfermagem; Sexualidade; Idoso

D5 Processo de enfermagem; Sexualidade; Idoso; Envelhecimento

\section{$\mathrm{MeSH}$}

M1 Nursing diagnosis; Sexuality; Aged; Aging; Nursing process

M2 Nursing diagnosis; Sexuality; Aged

M3 Nursing diagnosis; Sexuality; Aging

M4 Nursing process; Sexuality; Aged

M5 Nursing process; Sexuality; Aged; Aging

Fonte: Elaboração própria

Após selecionar os 15 artigos que se enquadraram nos critérios de inclusão, os cinco primeiros autores realizaram a leitura crítico-reflexiva de todos os estudos com o objetivo de codificar e identificar os principais elementos que respondessem à questão de pesquisa. Esse processo seguiu as diretrizes propostas por Severino ${ }^{19}$ para a leitura, análise e interpretação de textos: delimitação da unidade de leitura, análise textual, análise temática, análise interpretativa, problematização e síntese pessoal. A síntese pessoal foi transferida para dois quadros sinópticos elaborados pelos autores: o quadro 2 que evidencia a categorização dos estudos selecionados e - quadro 3 que evidencia os diagnósticos de Enfermagem para cada evidência encontrada nos estudos. Ressalta-se que, por se configurar um estudo de revisão da literatura, não houve necessidade de aprovação do Comitê de Ética em Pesquisa, conforme Resolução no 466/2012 e 510/2016 do Conselho Nacional de Saúde. Além do mais, no intuito de garantir a qualidade desta revisão, seguiu-se rigorosamente todos os quesitos exigidos pelo checklist PRISMA ${ }^{18}$.

\section{RESULTADOS}

Dentre os artigos selecionados, prevaleceram aqueles publicados em periódicos brasileiros $(73,3 \%)^{20-30}$, com abordagem qualitativa $(46,6 \%)^{20,22-}$ 27 , seguido do delineamento transversal $(33,3 \%)^{21,31-}$ 34 e selecionados por meio da base Google Scholar $(46,6 \%)^{22,26-30,34}$, conforme quadro 2.

$\mathrm{O}$ quadro 3 demonstra as principais evidências dos estudos relacionadas à sexualidade dos idosos, além dos diagnósticos de enfermagem para cada evidência. Ressalta-se que os diagnósticos foram fundamentados de acordo com o pressuposto teórico da NANDA (2018-2020) ${ }^{12}$. Desse modo, considerando que a NANDA define os diagnósticos

de Enfermagem como um "julgamento clínico" ${ }^{12} \mathrm{e}$ que o Enfermeiro é o profissional legalmente e cientificamente habilitado para realizar esse julgamento, todos os autores com a referida formação na área leram os artigos selecionados, identificaram nos artigos as situações relacionadas à sexualidade dos idosos e, por meio delas, fundamentando-se no julgamento clínico, traçaram os diagnósticos de enfermagem, formados por seus tulos, fatores relacionados, características definidoras ou populações em risco.

Ressalta-se que, a leitura que os autores fizeram para identificar tais situações, pode ainda ser considerada como a primeira etapa do Processo de Enfermagem - a coleta de dados, que de acordo com a Resolução $358 / 2009^{35}$, trata-se de um "processo deliberado, sistemático e contínuo, realizado com o auxílio de métodos e técnicas variadas, que tem por finalidade a obtenção de informações sobre a pessoa, família ou coletividade humana e sobre suas respostas em um dado momento do processo saúde e doença". 


\section{Revista Electrónica Enfermeria Actual en costa Rica}

\section{Tabela 1}

Quantidade de estudos encontrados para cada combinação.

\begin{tabular}{ccccccccccc}
\hline $\begin{array}{c}\text { DeCS/ } \\
\text { MeSH }\end{array}$ & BVS & PUBMED & SCIELO & LILACS & BDENF & IBECS & $\begin{array}{c}\text { SCIENCE } \\
\text { DIRECT }\end{array}$ & SCOPUS & $\begin{array}{c}\text { WEB OF } \\
\text { SCIENCE }\end{array}$ & $\begin{array}{c}\text { GOOGLE } \\
\text { SCHOLAR }\end{array}$ \\
\hline D1 & 0 & 0 & 0 & 0 & 0 & 0 & 0 & 0 & 0 & 5 \\
D2 & 6 & 0 & 2 & 0 & 0 & 0 & 0 & 0 & 0 & 5 \\
D3 & 0 & 0 & 1 & 0 & 0 & 0 & 0 & 0 & 0 & 2 \\
D4 & 10 & 0 & 4 & 0 & 0 & 0 & 1 & 0 & 0 & 3 \\
D5 & 4 & 0 & 3 & 0 & 0 & 0 & 1 & 0 & 0 & 0 \\
M1 & 0 & 6 & 0 & 0 & 0 & 0 & 2.162 & 0 & 0 & 0 \\
M2 & 45 & 359 & 0 & 0 & 0 & 0 & 2.162 & 72 & 23 & 0 \\
M3 & 1 & 25 & 0 & 0 & 0 & 0 & 2.744 & 6 & 23 & 0 \\
M4 & 18 & 359 & 0 & 0 & 0 & 0 & 2,744 & 51 & 23 & 0 \\
M5 & 7 & 14 & 0 & 0 & 0 & 0 & 2.744 & 2 & 23 & 0 \\
\hline TOTAL & 91 & 763 & 10 & 0 & 0 & 0 & 12.558 & 131 & 92 & 15 \\
\hline
\end{tabular}

Fonte: Elaboração própria

\section{Figura 1}

Fluxograma do percurso metodológico.

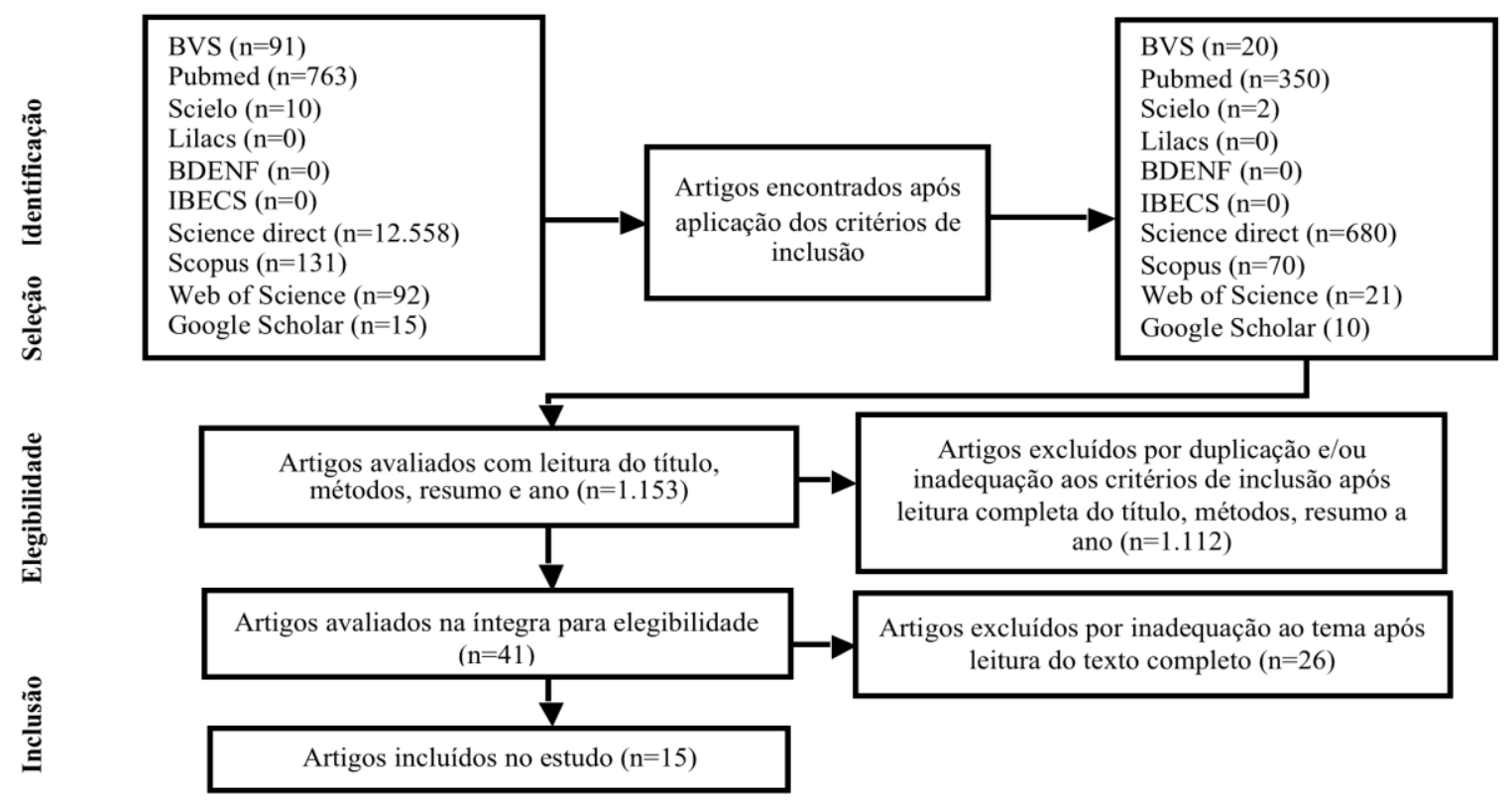

Fonte: Elaboração própria 


\section{Revista Electrónica Enfermeria Actual en costa Rica}

\section{Quadro 2}

Categorização dos estudos selecionados.

\begin{tabular}{|c|c|c|c|c|c|}
\hline № & Autores (ano) & Objetivo(s) & Métodos & Periódico & $\begin{array}{l}\text { Base de } \\
\text { dados }\end{array}$ \\
\hline 1 & $\begin{array}{l}\text { Alencar RA, Ciosak } \\
\text { SI }(2016)^{20}\end{array}$ & $\begin{array}{l}\text { Investigar entre os idosos vivendo com HIV/Aids e } \\
\text { os profissionais de saúde, quais são os motivos que } \\
\text { levam ao diagnóstico tardio da infecção pelo HIV } \\
\text { nos idosos }\end{array}$ & $\begin{array}{l}\text { Estudo prospectivo } \\
\text { e qualitativo }\end{array}$ & $\begin{array}{l}\text { Revista } \\
\text { Brasileira de } \\
\text { Enfermagem }\end{array}$ & Scielo \\
\hline 2 & $\begin{array}{l}\text { Okuno MFP, Fram } \\
\text { DS, Batista REA, } \\
\text { Barbosa DA, } \\
\text { Belasco AGS } \\
(2012)^{21}\end{array}$ & $\begin{array}{l}\text { Avaliar o conhecimento e atitudes sobre } \\
\text { sexualidade em idosos com HIV/AIDS atendidos em } \\
\text { ambulatório especializado; e identificar o perfil } \\
\text { epidemiológico desses pacientes }\end{array}$ & $\begin{array}{l}\text { Estudo de corte } \\
\text { transversal, } \\
\text { descritivo e } \\
\text { analítico }\end{array}$ & $\begin{array}{l}\text { Acta Paulista de } \\
\text { Enfermagem }\end{array}$ & Scielo \\
\hline 3 & $\begin{array}{l}\text { Laroque MF, } \\
\text { Affeldt AB, Cardoso } \\
\text { DH, Souza GL, } \\
\text { Santana MG, Lange } \\
\text { C }(2011)^{23}\end{array}$ & $\begin{array}{l}\text { Identificar o comportamento de idosos na } \\
\text { prevenção das DST/AIDS }\end{array}$ & $\begin{array}{l}\text { Estudo qualitativo, } \\
\text { exploratório e } \\
\text { descritivo }\end{array}$ & $\begin{array}{l}\text { Revista Gaúcha } \\
\text { de Enfermagem }\end{array}$ & Scielo \\
\hline 4 & $\begin{array}{l}\text { Lima CFM, Caldas } \\
\text { CP, Santos I, Trotte } \\
\text { LAC, Silva BMC } \\
(2017)^{24}\end{array}$ & $\begin{array}{c}\text { Compreender as transições vivenciadas, suas } \\
\text { condições e os padrões de resposta esperados a } \\
\text { mudanças na sexualidade do cônjuge-cuidador do } \\
\text { idoso em processo demencial }\end{array}$ & $\begin{array}{c}\text { Estudo exploratório, } \\
\text { de abordagem } \\
\text { qualitativa }\end{array}$ & $\begin{array}{l}\text { Revista } \\
\text { Brasileira de } \\
\text { Enfermagem }\end{array}$ & $\begin{array}{l}\text { Web of } \\
\text { Science }\end{array}$ \\
\hline 5 & $\begin{array}{l}\text { Van Hees PJ, Van } \\
\text { der Plas AA, Van Ek } \\
\text { GF, Putter H, Den } \\
\text { Oudsten BL, Den } \\
\text { Ouden MEM et al } \\
(2017)^{31}\end{array}$ & $\begin{array}{l}\text { Avaliar até que ponto os neurologistas discutem } \\
\text { sexualidade com pacientes com Doença de } \\
\text { Parkinson }\end{array}$ & Estudo transversal & $\begin{array}{l}\text { Journal of } \\
\text { Neural } \\
\text { Transmission }\end{array}$ & $\begin{array}{l}\text { Web of } \\
\text { Science }\end{array}$ \\
\hline 6 & $\begin{array}{l}\text { Heywood W, Lyons } \\
\text { A, Fileborn B, } \\
\text { Minichiello V, } \\
\text { Barrett C, Brown G } \\
\text { et al }(2017)^{32}\end{array}$ & $\begin{array}{c}\text { Fornecer dados detalhados sobre a testagem } \\
\text { autorreferida para rastreamento de Infecções } \\
\text { Sexualmente Transmissíveis, diagnósticos e fontes } \\
\text { de tratamento entre aqueles que pode estar em } \\
\text { risco de sofrer uma infecção e identificar correlatos } \\
\text { de testagens auto-relatadas de IST nos últimos } 5 \\
\text { anos }\end{array}$ & Estudo transversal & Sexual Health & Pubmed \\
\hline 7 & $\begin{array}{l}\text { Bezerra VP, Serra } \\
\text { MAP, Cabral IPP, } \\
\text { Moreira MASP, } \\
\text { Almeida SA, } \\
\text { Patrício ACFA } \\
(2015)^{25}\end{array}$ & $\begin{array}{l}\text { Conhecer a vulnerabilidade de idosos à infecção } \\
\text { pelo HIV no contexto das práticas preventivas }\end{array}$ & $\begin{array}{l}\text { Estudo exploratório } \\
\text { com abordagem } \\
\text { qualitativa }\end{array}$ & $\begin{array}{l}\text { Revista Gaúcha } \\
\text { de Enfermagem }\end{array}$ & Pubmed \\
\hline 8 & $\begin{array}{l}\text { Donnelly DW, } \\
\text { Donnelly C, } \\
\text { Kearney T, Weller } \\
\text { D, Sharp L, } \\
\text { Downing A et al } \\
(2018)^{33}\end{array}$ & $\begin{array}{l}\text { Fornecer dados sobre a prevalência de disfunção } \\
\text { urinária, intestinal e sexual na Irlanda do Norte, } \\
\text { atuar como base para estudos de resultados de } \\
\text { câncer de próstata e auxiliar na prestação de } \\
\text { serviços na população em geral }\end{array}$ & Estudo transversal & $\begin{array}{l}\text { British Journal of } \\
\text { Urology } \\
\text { International }\end{array}$ & Pubmed \\
\hline
\end{tabular}




\section{Revista Electrónica Enfermeria Actual en costa Rica}

\begin{tabular}{|c|c|c|c|c|c|}
\hline № & Autores (ano) & Objetivo(s) & Métodos & Periódico & $\begin{array}{l}\text { Base de } \\
\text { dados }\end{array}$ \\
\hline 9 & $\begin{array}{l}\text { Araújo BJ, Sales CO, } \\
\text { Cruz LFS, Moraes- } \\
\text { Filho IM, Santos OP } \\
\qquad(2017)^{26}\end{array}$ & $\begin{array}{c}\text { Verificar o entendimento sobre qualidade de vida e } \\
\text { investigar a sexualidade da população da terceira } \\
\text { idade em um grupo de idosos em uma cidade de } \\
\text { Goiás }\end{array}$ & $\begin{array}{l}\text { Pesquisa qualitativa } \\
\text { com abordagem } \\
\text { descritiva }\end{array}$ & $\begin{array}{c}\text { Revista de } \\
\text { Divulgação } \\
\text { Científica Sena } \\
\text { Aires }\end{array}$ & $\begin{array}{l}\text { Google } \\
\text { Scholar }\end{array}$ \\
\hline 10 & $\begin{array}{l}\text { Camargo BV, } \\
\text { Torres TL, Biasus F } \\
\qquad(2009)^{34}\end{array}$ & $\begin{array}{l}\text { Caracterizar práticas sexuais, atitudes de prevenção } \\
\text { e relação amorosa, além do nível de conhecimento } \\
\text { sobre HIV/Aids entre pessoas com mais de } 50 \text { anos } \\
\text { da região sul }\end{array}$ & $\begin{array}{l}\text { Estudo de natureza } \\
\text { descritiva e } \\
\text { comparativa, do } \\
\text { tipo transversal e } \\
\text { não randômico }\end{array}$ & $\begin{array}{l}\text { Revista de } \\
\text { Psicologia } \\
\text { LIBERABIT }\end{array}$ & $\begin{array}{l}\text { Google } \\
\text { Scholar }\end{array}$ \\
\hline 11 & $\begin{array}{l}\text { Gabriel GLL, Neves } \\
\text { S, Dias LG }(2010)^{27}\end{array}$ & $\begin{array}{l}\text { Conhecer a vivência e significado da sexualidade na } \\
\text { terceira idade, no referido grupo de convivência, } \\
\text { como subsídio ao cuidado de enfermagem; } \\
\text { Identificar a compreensão da sexualidade pelos } \\
\text { idosos participante do grupo; Descrever os fatores } \\
\text { que interferem na sexualidade e; Analisar as } \\
\text { estratégias de enfrentamento utilizadas pelos } \\
\text { idosos como subsídios no cuidado de enfermagem }\end{array}$ & $\begin{array}{l}\text { Pesquisa qualitativa } \\
\text { com abordagem } \\
\text { descritiva }\end{array}$ & $\begin{array}{l}\text { Revista de } \\
\text { Pesquisa: } \\
\text { Cuidado é } \\
\text { Fundamental } \\
\text { Online }\end{array}$ & $\begin{array}{l}\text { Google } \\
\text { Scholar }\end{array}$ \\
\hline 12 & $\begin{array}{l}\text { Andrade PBS, } \\
\text { Benito LAO } \\
(2016)^{28}\end{array}$ & $\begin{array}{c}\text { Analisar a sexualidade de pessoas idosas portadoras } \\
\text { de SIDA/AIDS atendidas em departamento } \\
\text { especializado }\end{array}$ & $\begin{array}{l}\text { Estudo exploratório, } \\
\text { descritivo e de } \\
\text { abordagem } \\
\text { quantitativa }\end{array}$ & $\begin{array}{l}\text { Universitas: } \\
\text { Ciências da } \\
\text { Saúde }\end{array}$ & $\begin{array}{l}\text { Google } \\
\text { Scholar }\end{array}$ \\
\hline 13 & $\begin{array}{l}\text { Rufino MRD, Arrais } \\
\text { AR }(2011)^{29}\end{array}$ & $\begin{array}{c}\text { Analisar as implicações psico-sócioculturais } \\
\text { da sexualidade para lidar com a AIDS na idade } \\
\text { avançada }\end{array}$ & $\begin{array}{l}\text { Pesquisa-ação de } \\
\text { natureza quanti- } \\
\text { qualitativa }\end{array}$ & $\begin{array}{l}\text { Revista Temática } \\
\text { Kairós } \\
\text { Gerontologia }\end{array}$ & $\begin{array}{l}\text { Google } \\
\text { Scholar }\end{array}$ \\
\hline 14 & $\begin{array}{c}\text { Santos NFV, } \\
\text { Formiga LMF, Silva } \\
\text { AKA, Mota MS, } \\
\text { Bezerra GSR, } \\
\text { Feitosa LMH } \\
(2017)^{30} \\
\end{array}$ & $\begin{array}{c}\text { Avaliar ações de educação em saúde sobre } \\
\text { sexualidade em idosos }\end{array}$ & $\begin{array}{c}\text { Estudo de } \\
\text { intervenção, } \\
\text { prospectivo, do tipo } \\
\text { antes e depois com } \\
\text { abordagem } \\
\text { quantitativa }\end{array}$ & Saúde em Redes & $\begin{array}{l}\text { Google } \\
\text { Scholar }\end{array}$ \\
\hline 15 & $\begin{array}{l}\text { Gois AB, Santos } \\
\text { RFL, Silva TPS, } \\
\text { Aguiar VFF (2017) }{ }^{22}\end{array}$ & $\begin{array}{l}\text { Conhecer a percepção de homens idosos acerca de } \\
\text { sua sexualidade }\end{array}$ & $\begin{array}{l}\text { Estudo descritivo } \\
\text { com uma } \\
\text { abordagem } \\
\text { qualitativa }\end{array}$ & $\begin{array}{l}\text { Enfermagem em } \\
\quad \text { Foco }\end{array}$ & $\begin{array}{l}\text { Google } \\
\text { Scholar }\end{array}$ \\
\hline
\end{tabular}




\section{Quadro 3}

Diagnósticos de Enfermagem para cada evidência encontrada nos estudos.

\begin{tabular}{|c|c|c|}
\hline № & Principais evidências dos estudos & Diagnósticos de Enfermagem (NANDA 2018-2020) ${ }^{12}$ \\
\hline $1^{20}$ & $\begin{array}{l}\text { *O diagnóstico tardio do HIV acontece na contramão } \\
\text { do serviço de saúde. } \\
\text { *Há invisibilidade da sexualidade do idoso. } \\
\text { *Há fragilidades na solicitação da sorologia anti-HIV } \\
\text { para os idosos. }\end{array}$ & $\begin{array}{l}\text {-Conhecimento deficiente caracterizado por conhecimento insuficiente relacionado às } \\
\text { informações insuficientes - (00126) } \\
\text {-Risco de infeç̧ão relacionado ao conhecimento insuficiente para evitar exposição a } \\
\text { patógenos (00004) } \\
\text {-Comunicação verbal prejudicada caracterizada por dificuldade para falar relacionada a } \\
\text { estímulos insuficientes e incongruência cultural (00051) }\end{array}$ \\
\hline $2^{21}$ & $\begin{array}{l}\text { * Evidenciou-se baixo nível de conhecimento sobre } \\
\text { sexualidade. }\end{array}$ & $\begin{array}{l}\text {-Conhecimento deficiente caracterizado por conhecimento insuficiente relacionado às } \\
\text { informações insuficientes (00126) } \\
\text {-Risco de infeç̧ão relacionado ao conhecimento insuficiente para evitar exposição a } \\
\text { patógenos (00004) } \\
\text {-Comunicação verbal prejudicada caracterizada por dificuldade para falar relacionada a } \\
\text { estímulos insuficientes e incongruência cultural (00051) }\end{array}$ \\
\hline $3^{23}$ & $\begin{array}{l}\text { *Observa-se grande resistência dos idosos quanto ao } \\
\text { uso do preservativo. } \\
\text { * Nenhum participante relatou diálogo com os } \\
\text { profissionais de saúde sobre sua sexualidade durante } \\
\text { as consultas. }\end{array}$ & $\begin{array}{l}\text {-Conhecimento deficiente caracterizado por conhecimento insuficiente relacionado às } \\
\text { informações insuficientes (00126) } \\
\text {-Comportamento de saúde propenso a risco caracterizado por falha em agir de forma a } \\
\text { prevenir problemas de saúde relacionado a compreensão inadequada (00188) } \\
\text { - Comunicação verbal prejudicada caracterizada por dificuldade para falar relacionada a } \\
\text { estímulos insuficientes e incongruência cultural (00051) } \\
\text {-Manutenção ineficaz da saúde caracterizada por ausência de interesse em melhorar } \\
\text { comportamentos de saúde e padrão de ausência de comportamento de busca de saúde } \\
\text { relacionada a habilidades de comunicação ineficazes (00099) } \\
\text {-Risco de infecção relacionado ao conhecimento insuficiente para evitar exposição a } \\
\text { patógenos (00004) } \\
\text {-Autonegligência caracterizada por falta de adesão a atividades de saúde relacionada a } \\
\text { escolha do estilo de vida (00193) }\end{array}$ \\
\hline $4^{24}$ & $\begin{array}{l}\text { *As mudanças na sexualidade conjugal em virtude do } \\
\text { processo demencial do idoso advêm de dificuldades } \\
\text { na manutenção da higiene, autoestima alterada e } \\
\text { hipersexualidade } \\
\text { *Identificou-se a necessidade de uma abordagem }\end{array}$ & $\begin{array}{l}\text {-Déficit no autocuidado para banho caracterizado por capacidade prejudicada de acessar } \\
\text { a fonte de água, acessar o banheiro, lavar o corpo, pegar os artigos para o banho, regular } \\
\text { a água do banho e secar o corpo relacionado a fraqueza e motivação diminuída (00108) } \\
\text {-Déficit no autocuidado para higiene íntima caracterizado por capacidade prejudicada de } \\
\text { chegar ao vaso sanitário, de dar descarga no vaso sanitário, de manipular as roupas para }\end{array}$ \\
\hline
\end{tabular}




\begin{tabular}{|c|c|c|}
\hline № & Principais evidências dos estudos & Diagnósticos de Enfermagem (NANDA 2018-2020) ${ }^{12}$ \\
\hline & $\begin{array}{l}\text { profissional sobre a sexualidade conjugal e o cuidado } \\
\text { ao idoso em processo demencial }\end{array}$ & $\begin{array}{l}\text { realizar a higiene íntima e de realizar a higiene íntima relacionado a fraqueza, mobilidade } \\
\text { prejudicada e motivação diminuída (00110) } \\
\text { Conforto prejudicado caracterizado por desconforto com a situação e descontentamento } \\
\text { com a situação relacionado ao controle situacional insuficiente (00214) } \\
\text {-Autonegligência caracterizada por higiene pessoal insuficiente relacionada a função } \\
\text { executiva deficiente (00193) } \\
\text {--Tensão do papel de cuidador caracterizada por falta de tempo para atender às } \\
\text { necessidades pessoais, frustração e indecisão emocional relacionados a condição de } \\
\text { saúde instável, condiçães físicas, energia insuficiente, padrão de relacionamentos } \\
\text { ineficazes e excesso de atividades de cuidado (00061) } \\
\text {-Comunicação verbal prejudicada caracterizada por dificuldade para falar relacionada a } \\
\text { estímulos insuficientes e incongruência cultural (00051) } \\
\text {-Relacionamento ineficaz caracterizado por apoio mútuo insuficiente nas atividades } \\
\text { cotidianas entre os parceiros e equilíbrio insuficiente na colaboração entre os parceiros } \\
\text { relacionados a estressores (00223) } \\
\text {-Sobrecarga de estresse caracterizada por aumento da impaciência, estresse excessivo, } \\
\text { sentir-se pressionado e tensão relacionado a estressores repetidos (00177) } \\
\text {-Padrão de sexualidade ineficaz caracterizado por alteração no comportamento sexual, } \\
\text { alteração no relacionamento com pessoa significativa, dificuldade com atividade sexual e } \\
\text { dificuldade com comportamento sexual relacionado ao conhecimento insuficiente sobre } \\
\text { alternativas relacionadas à sexualidade e relacionamento prejudicado com uma pessoa } \\
\text { significativa (00065) } \\
\text {-Risco de solidão relacionado a privação afetiva e privação emocional (00054) } \\
\text {-Risco de síndrome do idoso frágil relacionado a ansiedade, conhecimento insuficiente } \\
\text { sobre os fatores modificáveis, equilíbrio prejudicado e tristeza (00231) } \\
\text {-Risco de violência direcionada a si mesmo relacionado a conflito em relação(ões) } \\
\text { interpessoal(is) (00140) }\end{array}$ \\
\hline $5^{31}$ & $\begin{array}{l}\text { *A maioria dos participantes considerou importante } \\
\text { ou levemente importante a realização de triagem } \\
\text { para detectar disfunções sexuais } \\
\text { *A sexualidade é discutida com menos frequência em } \\
\text { pacientes com Doença de Parkinson do sexo } \\
\text { feminino e com pacientes com a mesma doença }\end{array}$ & $\begin{array}{l}\text {-Risco de infecção relacionado ao conhecimento insuficiente para evitar exposição a } \\
\text { patógenos (00004) } \\
\text {-Conhecimento deficiente caracterizado por conhecimento insuficiente relacionado às } \\
\text { informações insuficientes (00126) } \\
\text {-Comunicação verbal prejudicada caracterizada por dificuldade para falar relacionada a } \\
\text { estímulos insuficientes e incongruência cultural (00051) }\end{array}$ \\
\hline
\end{tabular}




\begin{tabular}{|c|c|c|}
\hline № & Principais evidências dos estudos & Diagnósticos de Enfermagem (NANDA 2018-2020) \\
\hline & acima de 70 anos & \\
\hline $6^{32}$ & $\begin{array}{l}\text { *Baixa taxa de testagem para deteç̧ão de IST } \\
\text { *Entre os homens, as taxas mais baixas foram } \\
\text { associadas à idade avançada e menor nível } \\
\text { educacional } \\
\text { *Para as mulheres, foram encontradas taxas mais } \\
\text { baixas entre as que não usaram preservativo em seu } \\
\text { encontro sexual mais recente }\end{array}$ & $\begin{array}{l}\text {-Conhecimento deficiente caracterizado por conhecimento insuficiente relacionado às } \\
\text { informações insuficientes (00126) } \\
\text {-Comportamento de saúde propenso a risco caracterizado por falha em agir de forma a } \\
\text { prevenir problemas de saúde relacionado a compreensão inadequada (00188) } \\
\text {-Manutenção ineficaz da saúde caracterizada por ausência de interesse em melhorar } \\
\text { comportamentos de saúde e padrão de ausência de comportamento de busca de saúde } \\
\text { relacionada a habilidades de comunicação ineficazes (00099) } \\
\text {-Risco de infecção relacionado ao conhecimento insuficiente para evitar exposição a } \\
\text { patógenos (00004) } \\
\text {-Autonegligência caracterizada por falta de adesão a atividades de saúde relacionada a } \\
\text { escolha do estilo de vida (00193) }\end{array}$ \\
\hline $7^{25}$ & $\begin{array}{l}\text { *Observa-se resistência ao uso do preservativo pela } \\
\text { população idosa } \\
\text { *Os idosos se constituem como grupos populacionais } \\
\text { mais vulneráveis à infecção pelo HIV e não se } \\
\text { reconheceram nesse cenário }\end{array}$ & $\begin{array}{l}\text {-Risco de infecção relacionado ao conhecimento insuficiente para evitar exposição a } \\
\text { patógenos (00004) } \\
\text {-Comportamento de saúde propenso a risco caracterizado por falha em agir de forma a } \\
\text { prevenir problemas de saúde relacionado a compreensão inadequada (00188) } \\
\text {-Autonegligência caracterizada por falta de adesão a atividades de saúde relacionada a } \\
\text { escolha do estilo de vida (00193) } \\
\text {-Manutenção ineficaz da saúde caracterizada por ausência de interesse em melhorar } \\
\text { comportamentos de saúde e padrão de ausência de comportamento de busca de saúde } \\
\text { relacionada a habilidades de comunicação ineficazes (00099) } \\
\text {-Conhecimento deficiente caracterizado por conhecimento insuficiente relacionado às } \\
\text { informações insuficientes (00126) }\end{array}$ \\
\hline $8^{33}$ & $\begin{array}{l}\text { *32,8\% dos homens com idade superior a } 60 \text { anos } \\
\text { relataram disfunção sexual }\end{array}$ & $\begin{array}{l}\text {-Risco de baixa autoestima situacional relacionado a alteração da imagem corporal } \\
\text { (00153) } \\
\text {-Distúrbio na imagem corporal caracterizado pela alteração na função corporal, alteração } \\
\text { na visão do próprio corpo, medo da reação dos outros, mudança no envolvimento social, } \\
\text { sentimento negativo em relação ao corpo, e Trauma em relação a não funcionamento de } \\
\text { parte do corpo relacionado a alteração na autopercepção (00118) } \\
\text {-Padrão de sexualidade ineficaz caracterizado por alteração no comportamento sexual e } \\
\text { dificuldade com comportamento sexual relacionado ao conhecimento insuficiente sobre } \\
\text { alternativas relacionadas à sexualidade e déficit de habilidades sobre alternativas } \\
\text { relacionadas à sexualidade (00065) }\end{array}$ \\
\hline
\end{tabular}




\begin{tabular}{|c|c|c|}
\hline № & Principais evidências dos estudos & Diagnósticos de Enfermagem (NANDA 2018-2020) 12 \\
\hline & & $\begin{array}{l}\text {-Risco de resiliência prejudicada relacionado a vulnerabilidade percebida (00211) } \\
\text {-Risco de automutilação relacionado a alteração da imagem corporal, autoestima } \\
\text { prejudicada, sentimento negativo e sentir-se ameaçado com a perda de relacionamento } \\
\text { significativo (00139) }\end{array}$ \\
\hline $9^{26}$ & $\begin{array}{l}\text { *73,81\% dos entrevistados relataram dificuldades em } \\
\text { falar sobre sexo } \\
\text { *90,48\% dos entrevistados reconhecem a } \\
\text { importância do sexo com o nível de felicidade } \\
\text { * } 84,92 \% \text { dos entrevistados não usam preservativos } \\
\text { durante as relações sexuais }\end{array}$ & $\begin{array}{l}\text {-Comunicação verbal prejudicada caracterizada por dificuldade para falar relacionada a } \\
\text { estímulos insuficientes e incongruência cultural (00051) } \\
\text {-Risco de infeçãa relacionado ao conhecimento insuficiente para evitar exposição a } \\
\text { patógenos (00004) } \\
\text {-Comportamento de saúde propenso a risco caracterizado por falha em agir de forma a } \\
\text { prevenir problemas de saúde relacionado a compreensão inadequada (00188) } \\
\text {-Autonegligência caracterizada por falta de adesão a atividades de saúde relacionada a } \\
\text { escolha do estilo de vida (00193) } \\
\text {-Manutenção ineficaz da saúde caracterizada por ausência de interesse em melhorar } \\
\text { comportamentos de saúde e padrão de ausência de comportamento de busca de saúde } \\
\text { relacionada a habilidades de comunicação ineficazes (00099) }\end{array}$ \\
\hline $10^{34}$ & $\begin{array}{l}\text { *Os participantes mantêm relações sexuais sem } \\
\text { prevenção, mas não acreditam que este seja um } \\
\text { comportamento de risco } \\
\text { *Os homens são menos favoráveis à prevenção do } \\
\text { que as mulheres, chegando a enfatizar que isto, na } \\
\text { idade deles é desnecessário e inútil. } \\
\text { *68,8\% afirmam que conversam sobre sexo }\end{array}$ & $\begin{array}{l}\text {-Risco de infeç̧ão relacionado ao conhecimento insuficiente para evitar exposição a } \\
\text { patógenos (00004) } \\
\text {-Comportamento de saúde propenso a risco caracterizado por falha em agir de forma a } \\
\text { prevenir problemas de saúde relacionado a compreensão inadequada (00188) } \\
\text {-Autonegligência caracterizada por falta de adesão a atividades de saúde relacionada a } \\
\text { escolha do estilo de vida (00193) } \\
\text {-Manutenção ineficaz da saúde caracterizada por ausência de interesse em melhorar } \\
\text { comportamentos de saúde e padrão de ausência de comportamento de busca de saúde } \\
\text { relacionada a habilidades de comunicação ineficazes (00099) } \\
\text {-Disposição para conhecimento melhorado caracterizada por expressa desejo de } \\
\text { melhorar a aprendizagem (00161) } \\
\text {-Disposição para comunicação melhorada caracterizada por expressa desejo de melhorar } \\
\text { a comunicação }\end{array}$ \\
\hline $11^{27}$ & $\begin{array}{l}\text { *Os participantes possuem poucas informações } \\
\text { sobre a sexualidade } \\
\text { *Sobressalência da cultura machista, que prega a } \\
\text { valorização da sexualidade relacionada ao aspecto } \\
\text { físico, de demonstração de força e de virilidade como }\end{array}$ & $\begin{array}{l}\text {-Padrão de sexualidade ineficaz caracterizado por alteração no comportamento sexual e } \\
\text { dificuldade com comportamento sexual relacionado ao conhecimento insuficiente sobre } \\
\text { alternativas relacionadas à sexualidade e déficit de habilidades sobre alternativas } \\
\text { relacionadas à sexualidade (00065) } \\
\text {-Comunicação verbal prejudicada caracterizada por dificuldade para falar relacionada a }\end{array}$ \\
\hline
\end{tabular}




\begin{tabular}{|c|c|c|}
\hline № & Principais evidências dos estudos & Diagnósticos de Enfermagem (NANDA 2018-2020) ${ }^{12}$ \\
\hline & um dos fatores que interferem na sexualidade & $\begin{array}{l}\text { estímulos insuficientes e incongruência cultural (00051) } \\
\text {-Conhecimento deficiente caracterizado por conhecimento insuficiente relacionado a } \\
\text { informações insuficientes (00126) } \\
\text {-Risco de dignidade humana comprometida relacionado a compreensão insuficiente das } \\
\text { informações de saúde, estigmatização e incongruência cultural (00174) } \\
\text {-Risco de distúrbio na identidade pessoal relacionado a alteração no papel social, baixa } \\
\text { autoestima e incongruência cultural (00225) } \\
\text {-Risco de baixa autoestima situacional relacionado a alteração da imagem corporal e } \\
\text { alteração no papel social (00153) } \\
\text {-Risco de automutilação relacionado a alteração da imagem corporal, autoestima } \\
\text { prejudicada e sentimento negativo (00139) }\end{array}$ \\
\hline $12^{28}$ & $\begin{array}{l}\text { *60\% dos participantes acreditam que a masturbação } \\
\text { em excesso pode causar o aparecimento de confusão } \\
\text { mental e de demência em pessoas com mais de } 65 \\
\text { anos. }\end{array}$ & $\begin{array}{l}\text {-Conhecimento deficiente caracterizado por conhecimento insuficiente relacionado a } \\
\text { informações insuficientes (00126) }\end{array}$ \\
\hline $13^{29}$ & $\begin{array}{l}\text { *A maioria dos participantes alega ser sexualmente } \\
\text { ativo e conhece os meios de prevenção das Infecções } \\
\text { Sexualmente Transmissíveis, mas poucos o utilizam. } \\
\text { * Há prevalência no discurso de que a AIDS está } \\
\text { associada a "grupos de risco" e de comportamento } \\
\text { tido como imoral. }\end{array}$ & $\begin{array}{l}\text {-Conhecimento deficiente caracterizado por conhecimento insuficiente relacionado a } \\
\text { informações insuficientes (00126) } \\
\text {-Risco de dignidade humana comprometida relacionado a compreensão insuficiente das } \\
\text { informações de saúde, estigmatização e incongruência cultural (00174) } \\
\text {-Risco de infecção relacionado ao conhecimento insuficiente para evitar exposição a } \\
\text { patógenos (00004) } \\
\text {-Comportamento de saúde propenso a risco caracterizado por falha em agir de forma a } \\
\text { prevenir problemas de saúde relacionado a compreensão inadequada (00188) } \\
\text {-Autonegligência caracterizada por falta de adesão a atividades de saúde relacionada a } \\
\text { escolha do estilo de vida (00193) } \\
\text {-Manutenção ineficaz da saúde caracterizada por ausência de interesse em melhorar } \\
\text { comportamentos de saúde e padrão de ausência de comportamento de busca de saúde } \\
\text { relacionada a habilidades de comunicação ineficazes (00099) }\end{array}$ \\
\hline $14^{30}$ & $\begin{array}{l}\text { * O nível de conhecimento, atitude e prática dos } \\
\text { participantes sobre sexualidade ainda é deficitário }\end{array}$ & $\begin{array}{l}\text {-Conhecimento deficiente caracterizado por conhecimento insuficiente relacionado a } \\
\text { informações insuficientes (00126) } \\
\text {-Risco de infecção relacionado ao conhecimento insuficiente para evitar exposição a } \\
\text { patógenos (00004) }\end{array}$ \\
\hline
\end{tabular}


Desse modo, traçou-se 29 diagnósticos distribuídos nos seguintes domínios: Promoção da saúde 3(10,3\%); Atividade/repouso 3(10,3\%); Percepção/cognição 4(13,9\%); Autopercepção $5(17,2 \%)$; Papéis e relacionamentos 2(6,9\%); Sexualidade 1(3,4\%); Enfrentamento/tolerância ao estresse 3(10,3\%); Princípios da vida 2(6,9\%); Segurança/proteção $4(13,9 \%)$ e Conforto $2(6,9 \%)$, conforme descritos a seguir:

- Domínio 1 - Promoção da saúde: Comportamento de saúde propenso a risco (00188), Manutenção ineficaz da saúde (00099) e Risco de síndrome do idoso frágil (00231).

- Domínio 2 - Nutrição: Nenhum diagnóstico traçado.

- Domínio 3 - Eliminação e troca: Nenhum diagnóstico traçado.

- Domínio 4 - Atividade/repouso: Déficit no autocuidado para banho (00108), Déficit no autocuidado para higiene íntima (00110), Autonegligência (00193).

- Domínio 5 - Percepção/cognição: Comunicação verbal prejudicada (00051), Disposição para comunicação melhorada (00157), Conhecimento deficiente (00126) e Disposição para conhecimento melhorado (00161)

- Domínio 6 - Autopercepção: Risco de dignidade humana comprometida (00174), Desesperança (00124), Risco de distúrbio na identidade pessoal (00225), Risco de baixa autoestima situacional (00153), Distúrbio na imagem corporal (00118).

- Domínio 7 - Papéis e relacionamentos: Tensão do papel de cuidador (00061), Relacionamento ineficaz (00223).

- Domínio 8 - Sexualidade: Padrão de sexualidade ineficaz (00065).

- Domínio 9 - Enfrentamento/tolerância ao estresse: Sobrecarga de estresse (00177), Risco de resiliência prejudicada (00211), Risco de sentimento de impotência (00152).
- Domínio 10 - Princípios da vida: Conflito de decisão (00083), Sofrimento moral (00175).

- Domínio 11 - Segurança/proteção: Risco de infecção (00004), Risco de automutilação (00139), Risco de suicídio (00150), Risco de violência direcionada a si mesmo (00140).

- Domínio 12 - Conforto: Conforto prejudicado (00214), Risco de solidão (00054).

\section{DISCUSSÃO}

A promoção da saúde fundamenta-se no campo de formulações teóricas e se caracteriza como um espaço de ações práticas na realidade social. No contexto do Sistema Único de Saúde (SUS), trata-se de uma importante estratégia para fomentar mudanças no modelo de organização dos serviços, contribuindo de maneira significativa na prevenção de doenças ${ }^{36}$. Assim, dentre os diagnósticos de promoção da saúde, o comportamento de saúde propenso a risco (00188) foi identificado em seis estudos $^{23,25,26,29,32,34}$. Tal diagnóstico foi traçado considerando as evidências de que os idosos não se consideram população vulnerável às IST, possuem resistência quanto ao uso do preservativo e baixa taxa de testagem para rastreamento das referidas infecções.

Esses resultados

demonstram imprescindibilidade de atenção especial a esses fatores durante a assistência em saúde da população idosa, especialmente da Atenção Primária, pois diversos estudos ${ }^{10,37-40}$ vêm alertando sobre o aumento da prevalência e incidência de IST nessa faixa etária. Além do mais, o número crescente dessas infeções na terceira idade refletem a ideia de que os próprios idosos, profissionais de saúde e sociedade acreditam que o envelhecimento reduz as chances de acometimento por alguma infecção sexual, por considerarem que os idosos são assexuados $^{41}$. Em decorrência disso, ocorre a negligência da sexualidade entre esse grupo, o que 


\section{Revista Electrónica Enfermeria Actual en costa Rica}

favorece a manutenção do comportamento de risco e a cadeia de transmissão.

Em relação ao Domínio Atividade/Repouso, os diagnósticos Déficit no autocuidado para banho (00108) e Déficit no autocuidado para higiene íntima, foi traçado conforme as evidências encontradas em um estudo ${ }^{24}$ que aborda a sexualidade do cônjugecuidador do idoso em processo demencial. Os idosos que vivem com demência podem ter sua sexualidade preservada e desfrutada conforme a disposição e adaptação às limitações impostas pelo declínio cognitivo. Desse modo, os profissionais de saúde devem também considerar essa população como sexualmente ativa e prover meios para desfrutar a sexualidade como forma de promoção e proteção da saúde. Sustenta-se esse argumento em alguns estudos que evidenciam benefícios da sexualidade para os idosos com demência como a redução do impacto da demência na vida do casal $^{42}$, melhor saúde mental e qualidade de vida ${ }^{43}$, redução das taxas de solidão ${ }^{43}$, além de potencializar a saúde e o bem-estar desses idosos ${ }^{44}$.

Entretanto, vale ressaltar que os idosos que cursam com algum tipo de demência podem ter alterações comportamentais evidenciadas por hipersexualidade, considerada um estado mórbido ${ }^{8}$. Esse estado de hipersexualidade pode se expressar através de atos libidinosos e expressões verbais sexualmente explícitas, nos quais devem ser reprimidos $^{8,45}$. Portanto, ela não preenche os critérios para ser considerada uma sexualidade saudável e precisa de intervenção médica para sua redução.

No que concerne ao Domínio Percepção/Cognição, o diagnóstico Comunicação verbal prejudicada (00051) foi evidenciada em sete estudos $^{20,21,23,24,26,27,31}$, em que se observou resistência dos idosos em falar sobre a sexualidade com profissionais ou familiares ${ }^{23,26}$, a questão da invisibilidade da sexualidade do idoso ${ }^{20}$, baixo nível de conhecimento sobre sexualidade 21,27 e necessidade de abordagem profissional sobre sexualidade ${ }^{24,31}$. Outro diagnóstico encontrado nesse domínio foi a Disposição para comunicação melhorada (00157) traçada por meio de evidências encontradas em dois estudos ${ }^{21,34}$. As evidências foram: o diálogo sobre sexualidade presente entre $68,8 \%$ dos idosos $^{34}$ e a confirmação de que os idosos com maior grau de instrução evidenciaram mais atitudes favoráveis à sexualidade ${ }^{21}$.

A literatura evidencia constantes barreiras encontradas na comunicação entre idosos e profissionais da saúde. Dentre elas, a deficiência na formação acadêmica sobre a geriatria e gerontologia é identificada como um dos principais obstáculos ${ }^{46}$. Em decorrência disso, a maioria dos profissionais da Atenção Básica não adota a sexualidade como abordagem assistencial durante suas consultas devido a reprodução de práticas estritamente curativistas com foco central nos processos patológicos ${ }^{47}$. A comunicação em saúde é uma ferramenta estratégica no SUS que orienta a tomada de decisão e o desenvolvimento de práticas assistenciais voltadas à promoção da saúde ${ }^{48}$. Desse modo, pode-se afirmar que, dentre as principais funções da comunicação, destacam-se o entendimento do mundo e de algumas dimensões que nos cercam, o relacionamento com as demais pessoas e a autotransformação. Para o alcance da efetividade de uma comunicação, é necessário que haja interação entre o emissor e receptor para que toda a informação seja, de fato, compreendida ${ }^{49}$.

Além do mais, para que ocorra uma comunicação efetiva, torna-se necessário a criação de vínculos, mas percebe-se que os profissionais apresentam dificuldades em se aproximarem dos usuários ao ponto de investigar com maior profundidade as suas necessidades e investir no fortalecimento do vínculo. Os próprios usuários relatam que não se sentem acolhidos quando recorrem aos serviços de saúde e 


\section{Revista Electrónica Enfermería Actual en costa Rica}

alegam falta de qualificação profissional que atenda às suas demandas ${ }^{50}$. Um estudo ${ }^{51}$ realizou um percurso cuidativo-educativo dialógico sobre sexualidade com mulheres idosas. As estratégias utilizadas por esses autores permitiram alcançar a eficácia da comunicação de tal modo que se mostraram como importantes ferramentas de cuidado, pois possibilitaram romper com o preconceito referente à sexualidade na terceira idade, promover a saúde das idosas e revelar novas formas de cuidar ${ }^{51}$.

No que diz respeito ao Domínio Autopercepção, nota-se os diagnósticos mais prevalentes: Risco de dignidade humana comprometida (00174) 22,27,29, Risco de baixa autoestima situacional $(00153)^{22,27,33} \mathrm{e}$ Risco de distúrbio na identidade pessoal $(00225)^{22,27}$. Esses três diagnósticos compartilham evidências em comum que são a predominância da cultura machista no campo da sexualidade, associando-a à força, virilidade e aspectos físicos ${ }^{27}$; além da presença de patologias, modificações fisiológicas e o preconceito da família ${ }^{22}$ que interferem na expressão da sexualidade entre os idosos. Cita-se além disso, a disfunção sexual ${ }^{33}$, que pode gerar perda de autoestima e repercutir de forma significativa nos aspectos relacionados à autopercepção e perda da identidade pessoal, saúde, bem-estar e qualidade de vida, tanto na população feminina ${ }^{52-55}$ quanto na masculina ${ }^{56-58}$.

Há ainda a prevalência no discurso de que a AIDS está associada a "grupos de risco" e de comportamento tido como imoral ${ }^{29}$. Esse discurso favorece com que os idosos se exponham a maior risco de adquirir IST, visto que, em seus pensamentos (autopercepção), estariam livres dessas doenças pois os mesmos acreditam não adotar práticas consideradas imorais, justificando, desta forma, o não uso de preservativos.

Em relação ao Domínio Papéis e Relacionamentos, traçou-se os diagnósticos Relacionamento ineficaz
(00223) e Tensão do papel de cuidador (00061) entre casais em que um dos cônjuges sofre demência ${ }^{24}$. No contexto dos idosos sem alterações demenciais, diversos estudos $2,22,46,59$ apontam a família como obstáculo, inibindo os idosos de vivenciarem sua sexualidade de maneira livre e plena. Nesta perspectiva, o enfermeiro deve estar atento a esses processos familiares e trabalhar de forma educativa a sexualidade com o as famílias de sua área de abrangência. Quando se trata de idosos com demência, deve-se considerar as repercussões da doença no contexto familiar, especialmente no membro que assume o papel de cuidador. As famílias cuidadoras acompanham toda a evolução da doença, expressadas por alterações físicas, cognitivas e comportamentais que interferem na rotina de cuidados e no campo afetivo, exigindo, portanto, mudanças de atitudes e comportamentos tanto do idoso quanto do cuidador que precisa se adaptar em cada fase do processo demencial ${ }^{60}$.

Essa adaptação, que apresenta uma característica progressiva, pode gerar sobrecarga nos familiares cuidadores, principalmente quando se trata do cônjuge cuidador. Como consequência dessa sobrecarga, os laços afetivos entre o casal podem sofrer influência justamente pela inversão de papeis observadas entre o ser que cuida e o ser que é cuidado.

No Domínio Sexualidade, foram traçados o diagnóstico Padrão de sexualidade ineficaz (00065) em quatro estudos $22,24,27,33$, relacionados à sobrecarga do cônjuge cuidador do idoso com doença de Alzheimer ${ }^{24}$; disfunção sexual ${ }^{33}$; associação errônea da sexualidade apenas para as pessoas jovens, viris e com porte físico condizente com os padrões de beleza impostos pela sociedade ${ }^{27}$; além do preconceito da família e das alterações fisiológicas, patológicas e biológicas expressadas pelos idosos 22 . 


\section{Revista Electrónica Enfermeria Actual en costa Rica}

Possivelmente, considerando a importância da sexualidade entre a população idosa, a ciência avançou nos últimos anos, desenvolvendo diversas opções terapêuticas para a disfunção sexual. Dentre as opções, cita-se as próteses penianas, psicoterapia, hormonioterapia, procedimentos cirúrgicos, medicamentos orais e injetáveis, dentre outros ${ }^{8}$. Além do mais, precisa-se abordar a sexualidade dos idosos contrapondo aos estereótipos da sexualidade impostos pela sociedade e, especialmente, pelas redes midiáticas, que desconsideram a velhice no contexto da sexualidade ${ }^{61}$. Com isso, torna-se importante sustentar as práticas profissionais nas dimensões do cuidado integral em saúde e estimular os idosos a vivenciarem todas as dimensões da vida que lhes proporcionem bem-estar ${ }^{2}$.

No que se refere ao Enfrentamento/Tolerância ao estresse, predominou-se o diagnóstico Risco de resiliência prejudicada (00211) evidenciada em dois estudos $^{22,33}$ referentes à disfunção sexual ${ }^{33}$ e as alterações biológicas, fisiológicas, patologias e preconceito da família ${ }^{22}$ que se destacaram por serem obstáculos que inibem a sexualidade dos idosos. A definição de resiliência vem sendo incorporada em diversos campos do conhecimento. Trata-se de um conceito originado na física, definindo-a como a capacidade de um determinado corpo em readquirir suas propriedades após modificações em sua forma primária oriundas de um agente externo ${ }^{62}$. Na saúde, indivíduos poucos resilientes, possuem maior exposição ao estresse e enfrentamento insuficiente frente às adversidades. Em decorrência disso, pode-se desenvolver sintomas depressivos, baixa autoestima, ansiedade, raiva e impulsividade ${ }^{63}$.

No Domínio Princípio da Vida predominou o diagnóstico Conflito de decisão (00083) em um estudo $^{22}$, associado especialmente aos dilemas entre a permissão e negação da vivência da sexualidade frente aos preconceitos familiares. Define-se conflito de decisão como um estado de incerteza sobre o percurso de uma determinada ação. Além do mais, considera-se que o nível de incerteza é maior quando há confronto entre decisões que abrangem aspectos relacionados a altos riscos e benefícios, incerteza nos resultados e mudanças nos valores pessoais $^{64}$. Vale ressaltar que, a família se posiciona como uma importante fonte de apoio e incentivo aos idosos. Entretanto, observa-se que a família reforça o preconceito sobre a sexualidade na velhice, ridicularizando-a e induzindo os idosos a reprimirem seus desejos. Em decorrência desse processo familiar, os idosos criam resistência na comunicação e não dialogam sobre $o$ assunto com seus familiares $^{22}$.

No que concerne ao Domínio Segurança/proteção, predominou-se nesse domínio o diagnóstico Risco de infecção (00004) em 10 estudos 20,21,23,25,26,29-32,34 associados à resistência e/ou não utilização do preservativo ${ }^{23,26,31,34}$ baixa taxa de realização de testes rápidos ${ }^{32}$, pouca valorização aos testes de rastreamento ${ }^{31}$, não se consideram como vulneráveis às $\mathrm{IST}^{25,29}$, e deficiência no conhecimento sobre a sexualidade e/ou infecções por via sexual ${ }^{20,21,30}$.

Já no Domínio conforto, houve predominância dos diagnósticos Conforto prejudicado $(00214)^{22,24} \mathrm{e}$ Risco de solidão $(00054)^{22,24}$, associados à sexualidade do cônjuge cuidador de idoso com doença de Alzheimer ${ }^{24}$ e nas questões referentes aos idosos que convivem com o preconceito familiar ${ }^{22}$. Essas situações geradoras de estresse e sobrecarga psicossocial podem trazer impactos nas relações afetivas e sexuais dos idosos, o que demonstra a necessidade de maior atenção aos idosos que lidam com processos demenciais e convivem com famílias disfuncionais.

Vale ressaltar que, embora tenhamos traçado 29 diagnósticos de enfermagem, podem existir outros diagnósticos relacionados à temática, que não foram evidenciados no presente estudo devido a limitação 


\section{Revista Electrónica Enfermería Actual en costa Rica}

quantitativa de artigos que investigam a sexualidade na terceira idade, o que impossibilitou a identificação de mais evidências que sustentassem a identificação de mais diagnósticos. Por conseguinte, acredita-se que a incorporação de práticas baseadas em evidências concernentes à sexualidade dos idosos podem ser uma ferramenta útil na identificação de mais diagnósticos e evidências relacionadas à sexualidade na velhice.

Esse estudo apresenta potencial para nortear e facilitar a assistência de enfermagem frente à sexualidade desse grupo etário, abordando os principais diagnósticos de enfermagem traçados a partir das evidências encontradas em artigos originais, nacionais e internacionais. Não obstante, sugere-se que estudos futuros revelem intervenções de enfermagem eficazes relacionadas à sexualidade de idosos e com isso, fortaleçam a proposta de envelhecimento ativo.

\section{CONCLUSÃO}

A maioria das situações relacionadas à sexualidade dos idosos encontradas no presente estudo foram as relacionadas com a autopercepção, o que nos permitiu traçar os diagnósticos de enfermagem com maior prevalência do Domínio 6 - Autopercepção da NANDA. Nesse domínio, foram traçados os seguintes títulos dos diagnósticos: Risco de dignidade humana comprometida (00174), Desesperança (00124), Risco de distúrbio na identidade pessoal (00225), Risco de baixa autoestima situacional (00153), Distúrbio na imagem corporal (00118).

Isso nos faz refletir sobre o poder que cada indivíduo detém, adquirido por meio da evolução de toda conjuntura político-social, que em diversas épocas moldam as suas crenças, atitudes e comportamentos. Nesta perspectiva, recomenda-se que a enfermagem deve estar atenta com mais profundidade aos aspectos que permeiam a subjetividade e os valores pessoais dos idosos, especialmente, os aspectos relacionados com a sexualidade nessa faixa etária para que de fato, seja alcançada a integralidade assistencial por meio de ações holísticas em saúde.

\section{CONFLITO DE INTERESSE}

Os autores declaram não haver conflitos de interesses

\section{REFERÊNCIAS}

1. Maataoui SL, Hardwick JS, Lundquist TS. Creating space for relationships. Psychol Serv. 2017; 14(3): 347-351. http://dx.doi.org/10.1037/ser0000179

2. Uchôa YS, Costa DCA, Silva Junior IAP, Silva STSE, Freitas WMTM, Soares SCS. Sexuality through the eyes of the elderly. Rev bras geriatr gerontol. 2016; 19(6): 939-49. https://doi.org/10.1590/1981-

22562016019.150189

3. Queiroz MAC, Lourenço RME, Coelho MMF, Miranda KCL, Barbosa RGB, Bezerra STF. Representações sociais da sexualidade entre idosos. Rev Bras Enferm. 2015; 68(4): 662-67. https://doi.org/10.1590/0034-7167.2015680413i

4.Shirin H. Sexuality and older people: a neglected issue, Reprod Health Matters. 2016; 24(48): 1-5. http://dx.doi.org/10.1016/j.rhm.2016.11.011

5. Evangelista AR, Moreira ACA, Freitas CASL, Val DR, Diniz JL, Azevedo SGV. Sexualidade de idosos: conhecimento/atitude de enfermeiros da Estratégia Saúde da Família. Rev Esc Enferm USP. 2019; 53: e03482.

http://dx.doi.org/10.1590/S1980-

220X2018018103482

6. Araújo SL, Zazula R. Sexualidade na terceira idade e terapia comportamental: revisão integrativa. RBCEH. 2015; 12(2): 172-82. http://dx.doi.org/10.5335/rbceh.v12i2.5054

7. Lee DM, Nazroo J, O'Connor DB, et al. Sexual health and well-being among older men and 
women in England: findings from the English Longitudinal Study of Ageing. Arch Sex Behav. 2016; 45(1):

133-144. http://dx.doi.org/10.1007/s10508-014-0465-1

8. Souza Júnior EV, Silva CS, Lapa PS, Trindade LES, Silva Filho BF, Sawada NO. Influence of Sexuality on the Health of the Elderly in Process of Dementia: Integrative Review. Aquichan. 2020; 20(1): e2016. https://doi.org/10.5294/aqui.2020.20.1.6

9. Chen $\mathrm{Y}-\mathrm{H}$, Jones $\mathrm{C}$, Osborne D. Exploratory study of Australian aged care staff knowledge and attitudes of later life sexuality. Australas J Ageing. 2017;36(2):E35-8. https://doi.org/10.1111/ajag.12404

10. Aguiar RB, Leal MCC, Marques APO, Torres KMS, Tavares MTDB. Idosos vivendo com HIV comportamento e conhecimento sobre sexualidade: revisão integrativa. Ciênc saúde coletiva. 2020; 25(2): 575-84. https://doi.org/10.1590/1413-

81232020252.12052018

11. Cunha GH, Ramalho AKL, Cruz AMM, Lima MAC, Franco KB, Lima RCRO. Diagnósticos de enfermagem segundo a teoria do autocuidado em pacientes com infarto do miocárdio. Aquichan. 2018; 18(2): 222-33. http://dx.doi.org/10.5294/aqui.2018.18.2.9

12. NANDA International. Diagnósticos de Enfermagem da NANDA-I: Definições e Classificação - 2018/2020 [Internet]. 2018 [cited 2021 Feb 16]. Available from: http://www.faesb.edu.br/biblioteca/wpcontent/uploads/2020/03/NANDA-I2018_2020.pdf

13. Silva DVA, Sousa INM, Rodrigues CAO, Pereira FAF, Gusmão ROM, Araújo DD. Diagnósticos de enfermagem em programa domiciliar: mapeamento cruzado e Taxonomia da NANDA-I.
Rev Bras Enferm. 2019; 72(3): 584-91. https://doi.org/10.1590/0034-7167-2018-0323

14. Karaca T, Aslan S. Effect of 'nursing terminologies and classifications' course on nursing students' perception of nursing diagnosis. Nurse educ today. 2018; 67: 114-17. https://doi.org/10.1016/j.nedt.2018.05.011

15. Ercole FF, Melo LS, Alcoforado CLGC. Integrative review versus systematic review. Rev Min Enferm. 2014; 18(1): 9-12. http://dx.doi.org/10.5935/1415-2762.20140001

16. Santos CM, Pimenta CA, Nobre M. A estratégia PICO para a construção da pergunta de pesquisa e busca de evidências. Rev Lat Am Enfermagem. 2007; 15(3):

508-11.

https://doi.org/10.1590/S0104-

11692007000300023

17. Bauer M, Fetherstonhaugh D, Tarzia L, Nay R, Beattie E. Supporting residents' expression of sexuality: the initial construction of a sexuality assessment tool for residential aged care facilities. BMC Geriatr. 2014;14:82. DOI: https://doi.org/10.1186/1471-2318-14-82

18. Equator Network. Preferred reporting items for systematic reviews and meta-analyses: The PRISMA statement [Internet]. Vol. 6. 2021 [cited 2021 Feb 16]. Available from: https://www.equator-network.org/reportingguidelines/prisma/

19. Severino AJ. Diretrizes para a leitura, análise e interpretação do trabalho científico. In: Cortez, editor. Metodologia do Trabalho Científico. São Paulo: Cortez; 2007. p. 153.

20. Alencar RA, Ciosak SI. Aids in the elderly: reasons that lead to late diagnosis. Alencar RA, Ciosak SI. AIDS in the elderly: reasons that lead to late diagnosis. Rev Bras Enferm. 2016; 69(6): 1076-81. http://dx.doi.org/10.1590/0034-7167-2016-0370

21. Okuno MFP, Fram DS, Batista REA, Barbosa DA, Belasco AGS. Conhecimento e atitudes sobre 
sexualidade em idosos portadores de HIV/AIDS*. Acta Paul Enferm. 2012; 25(spe1): 115-21. http://dx.doi.org/10.1590/S0103-

21002012000800018

22. Gois AB, Santos RFL, Silva TPS, Aguiar VFF. Percepção do homem idoso em relação a sua sexualidade. Enferm Foco. 2017; 8(3): 14-8. https://doi.org/10.21675/2357-

707X.2017.v8.n3.1024

23. Laroque MF, Affeldt AB, Cardoso DH, Souza GL, Santana MG, Lange C. Sexualidade do isoso: comportamento para a prevenção de DST/AIDS. Rev Gaúcha Enferm. 2011; 32(4): 774-80. http://dx.doi.org/10.1590/S1983-

14472011000400019

24. Lima CFM, Caldas CP, Santos I, Trotte LAC, Silva BMC. Therapeutic nursing care: transition in sexuality of the elderly caregiving spouse. Rev Bras Enferm. 2017; 70(4): 673-81. http://dx.doi.org/10.1590/0034-7167-2016-0256

25. Bezerra VP, Serra MAP, Cabral IPP, Moreira MASP, Almeida SA, Patrício ACFA. Práticas preventivas de idosos e a vulnerabilidade ao HIV. Rev Gaúcha Enferm. 2015; 36(4): 70-76. http://dx.doi.org/10.1590/1983-

1447.2015.04.44787

26. Araújo BJ, Sales CO, Cruz LFS, Moraes-Filho IM, Santos OP. Qualidade de vida e sexualidade na população da terceira idade de um centro de convivência. Rev Cient Sena Aires [internet]. 2017 [cited 2020 Jun 5]; 6(2): 85-94. Available from: http://revistafacesa.senaaires.com.br/index.php/ revisa/article/view/282/183

27. Gabriel GLL, Neves S, Dias LG. Sexualidade na vivência de idosos. $\mathrm{R}$ pesq cuid fundam online. 2010; 2(Ed. T20-24. http://dx.doi.org/10.9789/2175-

5361.rpcfo.v0.1105

28. Andrade PBS, Benito LAO. Perfil da sexualidade de pessoas idosas portadoras de SIDA/AIDS atendidas em um serviço de saúde do Distrito Federal. Universitas: Ciências da Saúde. 2016; 14(2):

105-13.

http://dx.doi.org/10.5102/ucs.v14i2.3812

29. Rufino MRD, Arrais AR. Sexualidade e AIDS na Velhice: novo desafio para a Universidade da Terceira Idade. Rev Kairós [internet]. 2011 [cited 2020 Jun 5]; 14(5): 221-41. Available from: https://revistas.pucsp.br/index.php/kairos/articl e/view/12736

30. Santos NFV, Formiga LMF, Silva AKA, Mota MS, Bezerra GSR, Feitosa LMH. Ações de educação em saúde sobre sexualidade com idosos. Saúde em Redes. 2017; 3(2): 162-71. https://doi.org/10.18310/2446-

48132017v3n2.828g151

31. Van Hees PJ, Van der Plas AA, Van Ek GF, Putter $H$, Den Oudsten BL, Den Ouden MEM et al. Discussing sexuality with patients with Parkinson's disease: a survey among Dutch neurologists. J Neural Transm (Vienna). 2017; 124(3): 361-8. http://dx.doi.org/10.1007/s00702-016-1655-x

32. Heywood W, Lyons A, Fileborn B, Minichiello V, Barrett $C$, Brown $G$ et al. Self-reported testing and treatment histories among older Australian men and women who may be at risk of a sexually transmissible infection. Sex Health. 2017; 14(2): 139-46. http://dx.doi.org/10.1071/SH16075

33. Donnelly DW, Donnelly C, Kearney T, Weller D, Sharp L, Downing A et al. Urinary, bowel and sexual health in older men from Northern Ireland. BJU Int. 2018; 122(5): 845-57. http://dx.doi.org/10.1111/bju.14182

34. Camargo BV, Torres TL, Biasus F. Práticas sexuais, conhecimento sobre hiv/aids e atitudes a respeito da relação amorosa e prevenção entre adultos com mais de 50 anos do sul do Brasil. Liber [internet]. 2009 [cited 2020 Jun 5]; 15(2): 171-80. Available from 
http://www.scielo.org.pe/scielo.php?script=sci_a rttext\&pid=S1729-48272009000200011

35. Conselho Federal de Enfermagem. Resolução Cofen 358/2009 [Internet]. 2009 [cited 2021 Feb 16]. Available from: http://mt.corens.portalcofen.gov.br/resolucaocofen-3582009_726.html

36. Carvalho FFB, Cohen SC, Akerman M. Refletindo sobre o instituído na Promoção da Saúde para problematizar 'dogmas'. Saúde debate. 2017; 41(spe3): 265-76. https://doi.org/10.1590/0103$11042017 \mathrm{~s} 320$

37. Cerqueira MBR, Rodrigues RN. Fatores associados à vulnerabilidade de idosos vivendo com HIV/AIDS em Belo Horizonte (MG), Brasil. Ciênc saúde colet. 2016; 21(11): 3331-8. https://doi.org/10.1590/1413-

812320152111.14472015

38. Tavares MCA, Leal MCC, Marques APO, Zimmermann RD. Apoio social aos idosos com HIV/aids: uma revisão integrativa. Rev bras geriatr gerontol. 2019; 22(2): e180168. https://doi.org/10.1590/1981-

22562019022.180168

39. Andrade J, Ayres JA, Alencar RA, Duarte MTC, Parada CMGL. Vulnerabilidade de idosos a infecções sexualmente transmissíveis. Acta paul enferm. 2017; 30(1): 8-15. https://doi.org/10.1590/1982-0194201700003

40. Conner LR, Fernández Y, Junious E, Piper C, Rowan D. Evaluating HIV Educational Materials for Older People. J Int Assoc Provid AIDS Care. 2019; 18: 1-10. https://doi.org/10.1177/2325958219849054

41. DeMarco RF, Brennan-Ing M, Sprague C, Brown SM. Ageism, Aging and HIV: Community Responses to Prevention, Treatment, Care and Support. Interdiscip Top Gerontol Geriatr. 2017; 42: 234-9. https://doi.org/10.1159/000448567
42. Lima CFM, Trotte LAC, Souza TA, Ferreira AMO, Caldas GP. Sexualidade do cônjuge que cuida do idoso demenciado: revisão integrativa da literatura. Rev Min Enferm. 2015; 19(2): 211-7. http://dx.doi.org/10.5935/1415-2762.20150036

43. Lindau ST, Dale W, Feldmeth G, Gavrilova N, Langa KM, Makelarski JA et al. Sexuality and Cognitive Status: A U.S. Nationally Representative Study of Home-Dwelling Older Adults. J Am Geriatr Soc. 2018; 66(10): 1902-10. http://dx.doi.org/doi:10.1111/jgs.15511

44. Cindy LAJ, Wendy M. Sexuality \& dementia: An eLearning resource to improve knowledge and attitudes of aged-care staff. Educational Gerontology. 2016; 42(8): 563-71. https://doi.org/10.1080/03601277.2016.120537 3

45. Giorgi R, Series H. Treatment of Inappropriate Sexual Behavior in Dementia. Curr Treat Options Neurol. 2016; 18 : 41. https://doi.org/10.1007/s11940-016-0425-2

46. Vieira KFL, Coutinho MPL, Saraiva ERD. A Sexualidade na velhice: representações sociais de idosos frequentadores de um Grupo de Convivência. Psicol Ciênc Prof. 2016; 36(1): 196$209 . \quad$ https://doi.org/10.1590/19823703002392013

47. Cabral NES, Pereira GCS, Souza US, Lima CFM, Santana GMS, Castañeda RFG. Compreensão de sexualidade por homens idosos de área rural. Rev baiana enferm. 2019; 33: e28165. https://doi.org/10.18471/rbe.v33.28165

48. Nardi ACF, Soares RAS, Mendonça AVM, Sousa MF. Comunicação em saúde: um estudo do perfil e da estrutura das assessorias de comunicação municipais em 2014-2015. Epidemiol Serv Saúde. 2018; 27(2): e2017409. https://doi.org/10.5123/s167949742018000200015 


\section{Revista Electrónica Enfermeria Actual en costa Rica}

49. Calsavara, VJ, Scorsolini-Comin F, Corsi CAC. A comunicação de más notícias em saúde: aproximações com a abordagem centrada na pessoa. Rev abordagem gestál. 2019; 25(1): 92102. https://doi.org/10.18065/RAG.2019v25.9

50. Almeida MM, Coutinho LS, Santos MS. Nurse as a hospital manager in primary care: integrative review. ReonFacema [internet]. 2017 [cited 2020 Jun 5]; 3(4): 765-74. Available from: https://www.facema.edu.br/ojs/index.php/ReOn Facema/article/view/273/158

51. Rodrigues DMMR, Labegalini CMG, Higarashi IH, Heidemann ITSB, Baldissera VDA. O percurso educativo dialógico como estratégia de cuidado em sexualidade com idosas. Esc Anna Nery. 2018; 22(3): e20170388. https://doi.org/10.1590/21779465-ean-2017-0388

52. Lara LAS, Scalco SCP, Troncon JK, Lopes GP. A Model for the Management of Female Sexual Dysfunctions. Rev Bras Ginecol Obstet. 2017; 39(4): 184-94. https://doi.org/10.1055/s-00371601435

53. Carteiro DMH, Sousa LMR, Caldeira SMA. Indicadores clínicos de disfunção sexual em mulheres grávidas: revisão integrativa de literatura. Rev Bras Enferm. 2016; 69(1): 165-73. https://doi.org/10.1590/0034-7167.2016690122i

54. Brasil APA, Abdo CHN. Transtornos sexuais dolorosos femininos. Diagn Tratamento [internet]. 2016 [cited 2020 Jun 5]; 21(2): 89-92. Available from: http://files.bvs.br/upload/S/1413-

9979/2016/v21n2/a5592.pdf

55. Correia LS, Brasil C, Silva MD, Silva DFC, Amorim HO, Lordêlo P. Função sexual e qualidade de vida de mulheres: um estudo observacional. Rev Port Med Geral Fam [Internet]. 2016 [cited 2020 Jun 5]; 32(6): 405-9. Available from: http://www.scielo.mec.pt/scielo.php?script=sci_ arttext\&pid=S2182-51732016000600007\&lng=pt
56. Tabosa A, Oliveira DC, Stangler VH, Araújo $H$, Nunes V, Gadelha Ml et al. Associação entre Disfunção Erétil e Piora na Qualidade de Vida de Pacientes com Doença Arterial Coronariana. Int J Cardiovasc Sci. 2017; 30(3): 21926. https://doi.org/10.5935/23594802.20170042

57. Azevedo C, Mata LRF, Braga PP, Chavez GM, Lopes MR, Penha CS. A percepção de homens e companheiras acerca da disfunção erétil pósprostatectomia radical. Texto contexto enferm. 2018; 27(1): e4870016. https://doi.org/10.1590/0104070720180004870016

58. Ferreira C, Gouveia M, Carmona S, Sanches R. Disfunção erétil: haverá melhoria com o exercício físico?. Rev Port Med Geral Fam [Internet]. 2017[cited 2020 Jun 5] ;33(6): 430-1. Available from:

http://www.scielo.mec.pt/scielo.php?script=sci_ arttext\&pid=S2182-51732017000600009\&lng=pt

59. Vilar DGR. A sexualidade das pessoas idosas vista pelas próprias. Intervenção Social. 2016; (47/48): 275-91. https://doi.org/10.34628/6r1e-ks51

60. Nascimento HG, Figueiredo AEB. Demência, familiares cuidadores e serviços de saúde: o cuidado de si e do outro. Ciênc saúde coletiva. 2019; 24(4): 1381-92. https://doi.org/10.1590/1413-

81232018244.01212019

61. Gewirtz-Meydan A, Hafford-Letchfield T, Ayalon L, Benyamini Y, Biermann V, Coffey A et al. Cult Health Sex. 2019; 21(3): 293-308. https://doi.org/10.1080/13691058.2018.146520 3

62. Hildebrand NA, Celeri EHRV, Morcillo AM, Zanolli ML. Resiliência e problemas de saúde mental em crianças e adolescentes vítimas de violência. Rev Saúde Pública. 2019; 53: 17. 
https://doi.org/10.11606/s1518-

8787.2019053000391

63. Carvalho IG, Santos Bertolli E, Paiva L, Rossi LA, Dantas RAS, Pompeo DA. Ansiedade, depressão, resiliência e autoestima em indivíduos com doenças cardiovasculares. Rev Lat Am Enfermagem. 2016;24:e2836. http://dx.doi.org/10.1590/1518-8345.1405.2836

64. Martinho MJCM, Silva Martins MMFP, Angelo M. Escala de conflito em tomadas de decisão em saúde: Instrumento adaptado e validado para língua portuguesa. Rev da Esc Enferm da USP. 2013;47(3):575-82.

https://doi.org/10.1590/S0080623420130000300008 